\title{
Complex Dynamics Analysis for a Cournot-Bertrand Mixed Game Model with Delayed Bounded Rationality
}

\author{
Junhai $\mathrm{Ma}^{1}$ and Hongwu Wang ${ }^{1,2}$ \\ ${ }^{1}$ School of Management, Tianjin University, Tianjin 300072, China \\ ${ }^{2}$ College of Science, Tianjin University of Science and Technology, Tianjin 300457, China \\ Correspondence should be addressed to Hongwu Wang; lzwhw2000@126.com
}

Received 18 June 2013; Accepted 19 August 2013

Academic Editor: Massimiliano Ferrara

Copyright (c) $2013 \mathrm{~J}$. Ma and H. Wang. This is an open access article distributed under the Creative Commons Attribution License, which permits unrestricted use, distribution, and reproduction in any medium, provided the original work is properly cited.

\begin{abstract}
A Cournot-Bertrand mixed duopoly game model is constructed. The existence and local stable region of the Nash equilibria point are investigated. Complex dynamic properties such as bifurcation and route to chaos are analyzed using parameter basin plots. The strange attractors are also studied when the system is in chaotic states. Furthermore, considering the memory of the market, a delayed Cournot-Bertrand mixed model is considered and the results show that the delayed system has the same Nash equilibrium and has a higher chance of reaching steady states or cycles than the model without delay. So making full use of the historical data can improve the system's stability.
\end{abstract}

\section{Introduction}

An Oligopoly is a market mechanism between monopoly and perfect competition, in which the market is completely controlled by only a few number of firms producing the same or homogeneous productions [1]. In recent years, the oligopoly game models have attracted many researchers' attention firstly because oligopoly is a common market structure and secondly because the models have different forms according to the difference of the real economic environments [2-4].

Cournot and Bertrand oligopoly are the two most notable models in oligopoly theory. In the first one, firms control their output level, which influences the market price, while in the second one, firms change the price to affect the market demand [5]. A large number of literatures about Cournot or Bertrand competition in oligopolistic market have been published $[3,4]$, but there are only a considerably lower number of works devoted to Cournot-Bertrand mixed competition, in which the market can be subdivided into two groups of firms, the first one optimally adjust prices and the second optimally adjusts their outputs to ensure maximum profit [6-8]. Cournot-Bertrand mixed models exist in realistic economy, and in some cases CournotBertrand competition may be optimal [7]. For instance, in duopoly market, one firm competes in a dominant position, and it chooses output as decision variable while the other one is in disadvantage, and it chooses price as decision variable in order to gain more market share [5].

To the best of our knowledge, Bylka and Komar [9] are the first authors to analyze Cornot-Bertrand mixed models. Vives [10], Sklivas [11], Häckner [12], Zanchettin [13], and Arya et al. [14] compared the efficiency of the Cournot and Bertrand models under different conditions. Sato [15] gave a Cournot-Bertrand mixed model under a set of regularity conditions on demand and cost and compared its equilibrium with the Cournot and Bertrand models. C. H. Tremblay and V. J. Tremblay [6] analyzed the role of product differentiation for the static properties of the Nash equilibrium of a CournotBertrand mixed duopoly. Naimzada and Tramontana [7] considered a Cournot-Bertrand mixed duopoly model, which is characterized by linear difference equations and analyzed the role of best response dynamics and of the adaptive adjustment mechanism for the stability of the equilibrium. Ma and $\mathrm{Pu}$ [8] studied complex behaviors of a Cournot-Bertrand mixed duopoly model with the application of nonlinear dynamics theory. Wang and $\mathrm{Ma}$ [5], based on the players with bounded rationality, proposed a Cournot-Bertrand mixed game model and discussed the stability of the system. 
Delay plays an important role in economic system, which can describe some economic phenomena and help solve a great deal of problems, such as the delay of fiscal policy's conduction behavior in macroeconomics. Ahmed et al. [16] considered the delay in oligopoly, showing that delay can increase stability, and firms using bounded rationality with delay have a higher chance of reaching Nash equilibrium. Agiza et al. [17] studied the stability of delayed Bowley's model with bounded rationality in monopoly. Yassen and Agiza [18] discussed the complexity of Bowley's model with delayed bounded rationality in duopoly. Hassan [19] investigated a delayed duopoly model, and the results showed that stability of Nash equilibrium is increased if less weight is put on the more recent quantity; otherwise, the region of stability is smaller. Elsadany [20] gave a duopoly delayed Cournot model and pointed out that delay has the effect of delaying a perioddoubling appearance. Matsumoto and Szidarovszky [21] examined a continuous delayed Cournot-Bertrand mixed model, and the results showed that the time lags have a destabilizing effect on the equilibrium. Peng et al. [22] and Ma and Zhang [23] separately studied a 3-dimensional delayed Cournot and Bertrand model and analyzed the effects of the adjustment of parameters on the stability of the systems.

In this paper, we set up a discrete Cournot-Bertrand duopoly model, assuming that the market has a linear demand function, and the firms are delayed bounded rational. The system's complex dynamics are analyzed through numerical simulations. Our work aims to check whether the delay can increase the stability of the Cournot-Bertrand mixed system, which modifies and extends the results of [1823], who considered the Cournot or Bertrand systems, and also [21], who considered a continuous delayed CournotBertrand mixed system.

The paper is organized as follows. The nondelayed and delayed Cournot-Bertrand mixed game models with bounded rational expectations are described in Section 2. In Section 3, we will study the complex dynamics of the nondelayed system, including the existence and local stability of equilibrium points and the bifurcation behaviors. Delayed system is investigated in Section 4 to find the effects of delay on the stability of the system. Finally, conclusions are drawn in Section 5.

\section{The Cournot-Bertrand Mixed Models with Bounded Rational Expectations}

Assuming that a market is served by two firms and firm $i$ produces good $x_{i}, i=1,2$. There is a certain degree of differentiation between the products $x_{1}$ and $x_{2}$ to avoid the whole market that is occupied by the one who offers a lower price. The output and price of firm is product are, respectively, represented as $q_{i}$ and $p_{i}$. Firm 1 competes in output $q_{1}$ to affect the market supply as the Cournot case, while firm 2 fixes its price $p_{2}$ to influence the market demand as in the Bertrand case.

The consumers' utility function is defined as follows:

$$
U\left(q_{1}, q_{2}\right)=a\left(q_{1}+q_{2}\right)-\frac{b}{2}\left(q_{1}^{2}+2 k q_{1} q_{2}+q_{2}^{2}\right)+M
$$

and the consumers' budget constraint is as follows:

$$
Y=M+p_{1} q_{1}+p_{2} q_{2}
$$

where $Y$ denotes the consumers' real disposable income, $M$ denotes expenditure on outside goods, and the parameter $k \in(0,1)$ denotes the degree of product differentiation or product substitution, while a negative $k \in(-1,0)$ implies that products are complements and $k=0$ implies that products are completely independent.

By maximizing the utility function equation (1) subject to the budget constraint equation (2), we can obtain the inverse demand functions of products of variety 1 and 2 at time $t$ as follows:

$$
\begin{aligned}
& p_{1}(t)=a-b q_{1}(t)-b k q_{2}(t), \\
& p_{2}(t)=a-b q_{2}(t)-b k q_{1}(t) .
\end{aligned}
$$

Rescale the variables

$$
P_{1}=\frac{p_{1}}{a}, \quad P_{2}=\frac{p_{2}}{a}, \quad Q_{1}=\frac{b}{a} q_{1}, \quad Q_{2}=\frac{b}{a} q_{2} .
$$

Then (3) can be rewritten as follows:

$$
\begin{aligned}
& P_{1}(t)=1-Q_{1}(t)-k Q_{2}(t), \\
& P_{2}(t)=1-Q_{2}(t)-k Q_{1}(t) .
\end{aligned}
$$

Assuming that the two firms have the same marginal cost $c>0$, and the cost function of firm $i$ is as follows:

$$
C_{i}\left(Q_{i}(t)\right)=c Q_{i}(t), \quad i=1,2 .
$$

We can write the demand functions equations (5) in the two strategic variables, $Q_{1}(t)$ and $P_{2}(t)$

$$
\begin{gathered}
P_{1}(t)=1-k-\left(1-k^{2}\right) Q_{1}(t)+k P_{2}(t), \\
Q_{2}(t)=1-P_{2}(t)-k Q_{1}(t) .
\end{gathered}
$$

Then the profit functions of firms 1 and 2 are, respectively, as follows:

$$
\begin{aligned}
\Pi_{1}(t)= & Q_{1}(t)\left(1-k+k P_{2}(t)-Q_{1}(t)+k^{2} Q_{1}(t)\right) \\
& -c Q_{1}(t) \\
\Pi_{2}(t)= & P_{2}(t)\left(1-P_{2}(t)-k Q_{1}(t)\right) \\
& -c\left(1-P_{2}(t)-k Q_{1}(t)\right)
\end{aligned}
$$

Assuming that the two firms do not have a complete knowledge of the market and the opponent, and in this case they make decisions on the basis of their expected marginal profits as follows:

$$
\begin{gathered}
\frac{\partial \Pi_{1}}{\partial Q_{1}}\left(Q_{1}^{e}, P_{2}^{e}\right)=1-c-k+k P_{2}^{e}-2 Q_{1}^{e}+2 k^{2} Q_{1}^{e}, \\
\frac{\partial \Pi_{2}}{\partial P_{2}}\left(Q_{1}^{e}, P_{2}^{e}\right)=1+c-2 P_{2}^{e}-k Q_{1}^{e},
\end{gathered}
$$


TABLE 1: The eigenvalues of the Jacobian matrix (14) evaluated at the boundary equilibrium points.

\begin{tabular}{lc}
\hline Equilibrium points & Eigenvalues \\
\hline$E_{0}$ & $\lambda_{1}=1+\beta(1+c), \lambda_{2}=1+\alpha(1-c-k)$ \\
$E_{1}$ & $\lambda_{1}=1+\alpha(1-c)(1-k / 2), \lambda_{2}=1-\beta(1+c)$ \\
$E_{2}$ & $\lambda_{1}=1+\beta N / 2\left(1-k^{2}\right), \lambda_{2}=1-\alpha(1-c-d)$ \\
\hline
\end{tabular}

Notes: $N=(1+2 c)\left(1-k^{2}\right)+c k+(1-k)$.

where $Q_{1}^{e}$ and $P_{2}^{e}$ are the expected output of firm 1 and price of firm 2, respectively. If the marginal profit is positive (negative), they increase (decrease) their output or price in the next period [4].

Supposing that the firms make decisions of period $t+1$ based on the variables of period $t$; that is, $Q_{1}^{e}=Q_{1}(t), P_{2}^{e}=$ $P_{2}(t)$; then, the nondelayed Cournot-Bertrand mixed dynamical system can be described by the first-order nonlinear difference equations:

$$
\begin{aligned}
Q_{1}(t+1)= & Q_{1}(t)+\alpha Q_{1}(t) \\
& \times\left(1-c-k+k P_{2}(t)-2 Q_{1}(t)+2 k^{2} Q_{1}(t)\right) \\
P_{2}(t+1)= & P_{2}(t)+\beta P_{2}(t)\left(1+c-2 P_{2}(t)-k Q_{1}(t)\right),
\end{aligned}
$$

where $\alpha>0$ and $\beta>0$ represent the two players' adjustment speed, respectively.

However, considering the learning ability of the firms' managers, when they make decisions, they depend on not only the marginal profits of period $t$, but also the past information, and this is known as the delayed bounded rational expectation $[16,19,20]$. In this case, the delayed Cournot-Bertrand mixed system with one-step delay, that is, $Q_{1}^{e}=\omega_{1} Q_{1}(t)+\left(1-\omega_{1}\right) Q_{1}(t-1), P_{2}^{e}=\omega_{2} P_{2}(t)+(1-$ $\left.\omega_{2}\right) P_{2}(t-1)$ where $\omega_{1}$ and $\omega_{2}$ are separately the weight factors of production and price, is given by the two-order nonlinear difference equations:

$$
\begin{aligned}
& Q_{1}(t+1) \\
& \begin{aligned}
&=Q_{1}(t)+\alpha Q_{1}(t) \\
& \times\left(\omega_{1}\left(1-c-k+k P_{2}(t)-2 Q_{1}(t)+2 k^{2} Q_{1}(t)\right)\right. \\
&+\left(1-\omega_{1}\right) \\
& \quad\left(1-c-k+k P_{2}(t-1)\right. \\
&\left.\left.\quad-2 Q_{1}(t-1)+2 k^{2} Q_{1}(t-1)\right)\right) \\
& P_{2}(t+1) \quad P_{2}(t)+\beta P_{2}(t) \\
& \quad\left(\omega_{2}\left(1+c-2 P_{2}(t)-k Q_{1}(t)\right)+\left(1-\omega_{2}\right)\right. \\
& \quad\left.\times\left(1+c-2 P_{2}(t-1)-k Q_{1}(t-1)\right)\right)
\end{aligned}
\end{aligned}
$$

$\omega_{1}, \omega_{2} \in(0,1]$. When $\omega_{1}=\omega_{2}=1$, the system (11) will become (10).

\section{The Dynamics of the Nondelayed Cournot-Bertrand Mixed System}

3.1. Equilibrium Points and Local Stability. Let $Q_{1}(t+1)=$ $Q_{1}(t)$ and $P_{2}(t+1)=P_{2}(t)$. The system (10) have four equilibrium points

$$
\begin{gathered}
E_{0}(0,0), \quad E_{1}\left(0, \frac{1+c}{2}\right), \\
E_{2}\left(\frac{1-c-k}{2\left(1-k^{2}\right)}, 0\right), \quad E^{*}\left(Q_{1}^{*}, P_{2}^{*}\right),
\end{gathered}
$$

where

$$
\begin{gathered}
Q_{1}^{*}=\frac{2-2 c-k+c k}{4-3 k^{2}}, \\
P_{2}^{*}=\frac{2+2 c-k+c k-k^{2}-2 c k^{2}}{4-3 k^{2}} .
\end{gathered}
$$

$E_{0}, E_{1}$, and $E_{2}$ are the boundary equilibrium points, and $E^{*}$ is the unique Nash equilibrium point provided that $Q_{1}^{*}>0$ and $P_{2}^{*}>0$, that requires $c<1$. Otherwise, there will be one firm out of the market.

The local stability of equilibrium points can be determined by the nature of the eigenvalues of the Jacobian matrix evaluated at the corresponding equilibrium points. The Jacobian matrix of the system (10) corresponding to the state variables $\left(Q_{1}, P_{2}\right)$ is as follows:

$$
J\left(Q_{1}, P_{2}\right)=\left(\begin{array}{cc}
J_{11} & \alpha k Q_{1} \\
-\beta k P_{2} & J_{22}
\end{array}\right),
$$

where

$$
\begin{gathered}
J_{11}=1+\alpha\left(1-c-k+k P_{2}+4\left(k^{2}-1\right) Q_{1}\right), \\
J_{22}=1+\beta\left(1+c-4 P_{2}-k Q_{1}\right) .
\end{gathered}
$$

Table 1 gives the eigenvalues of the Jacobian matrix (14) evaluated at the boundary equilibrium points, and we can easily conclude that $\lambda_{1}>1$ for $E_{0}, E_{1}$, and $E_{2}$, so the boundary equilibrium points are not stable.

From the view of economics, we are more interested in studying the local stability properties of the Nash equilibrium point $E^{*}$. With respect to the boundary equilibrium points, it is more difficult to explicitly calculate the eigenvalues of the Nash equilibrium, but it still possible to evaluate its stability by using the Jury conditions [24].

The Jacobian matrix at the Nash equilibrium point $E^{*}$ is as follows:

$$
\begin{aligned}
& J\left(E^{*}\right) \\
& =\left(\begin{array}{cc}
1-\frac{2 \alpha(1-c)\left(2-k-2 k^{2}+k^{3}\right)}{4-3 k^{2}} & \frac{\alpha k(c-1)(2-k)}{4-3 k^{2}} \\
\frac{\beta k\left(k+k^{2}-2-c\left(2+k-2 k^{2}\right)\right)}{4-3 k^{2}} & 1-\frac{2 \beta N}{4-3 k^{2}}
\end{array}\right) .
\end{aligned}
$$


We obtain that the trace and determinant of $J\left(E^{*}\right)$ are, respectively, as follows:

$$
\begin{gathered}
\operatorname{Tr}\left(J\left(E^{*}\right)\right)=2-\frac{2 \alpha(1-c)\left(2-k-2 k^{2}+k^{3}\right)+2 \beta N}{4-3 k^{2}}, \\
\operatorname{Det}\left(J\left(E^{*}\right)\right)=1+\frac{\alpha \beta(1-c)(2-k) N-2 \beta N}{4-3 k^{2}} .
\end{gathered}
$$

A necessary and sufficient condition for the locally stability of Nash equilibrium point $E^{*}$ is the following:

$$
\begin{aligned}
& \text { (i) } \quad A:=1+\operatorname{Tr}\left(J\left(E^{*}\right)\right)+\operatorname{Det}\left(J\left(E^{*}\right)\right)>0, \\
& \text { (ii) } B:=1-\operatorname{Tr}\left(J\left(E^{*}\right)\right)+\operatorname{Det}\left(J\left(E^{*}\right)\right)>0, \\
& \text { (iii) } \quad C:=1-\operatorname{Det}\left(J\left(E^{*}\right)\right)>0 .
\end{aligned}
$$

The local stable region of $E^{*}$ in $(\alpha, \beta)$ parameters plane can be obtained by solving the inequalities (18) as follows:

$$
\begin{aligned}
0<\alpha \leq & \frac{3 k^{2}-4}{(c-1)(k-2)\left(k^{2}-1\right)} \\
& -\sqrt{\frac{4 k^{2}-3 k^{4}}{(c-1)^{2}(k-2)^{2}\left(k^{2}-1\right)^{2}}},
\end{aligned}
$$

$0<\beta$

$$
\begin{aligned}
& <\frac{4\left(\alpha(c-1)\left(k^{3}-2 k^{2}-k+2\right)-3 k^{2}+4\right)}{\left(c\left(2 k^{2}-k-2\right)+k^{2}+k-2\right)(\alpha(c-1)(k-2)-4)} ; \\
& \frac{3 k^{2}-4}{(c-1)(k-2)\left(k^{2}-1\right)}-\sqrt{\frac{4 k^{2}-3 k^{4}}{(c-1)^{2}(k-2)^{2}\left(k^{2}-1\right)^{2}}} \\
& <\alpha \leq \frac{3 k^{2}-4}{(c-1)\left(k^{3}-2 k^{2}-k+2\right)},
\end{aligned}
$$$$
0<\beta
$$

$$
\begin{gathered}
<\frac{2 \alpha(c-1)\left(k^{3}-2 k^{2}-k+2\right)}{\left(c\left(2 k^{2}-k-2\right)+k^{2}+k-2\right)(\alpha(c-1)(k-2)-2)} ; \\
\frac{3 k^{2}-4}{(c-1)\left(k^{3}-2 k^{2}-k+2\right)} \\
<\alpha<\frac{3 k^{2}-4}{(c-1)(k-2)\left(k^{2}-1\right)} \\
+\sqrt{\frac{4 k^{2}-3 k^{4}}{(c-1)^{2}(k-2)^{2}\left(k^{2}-1\right)^{2}}}
\end{gathered}
$$

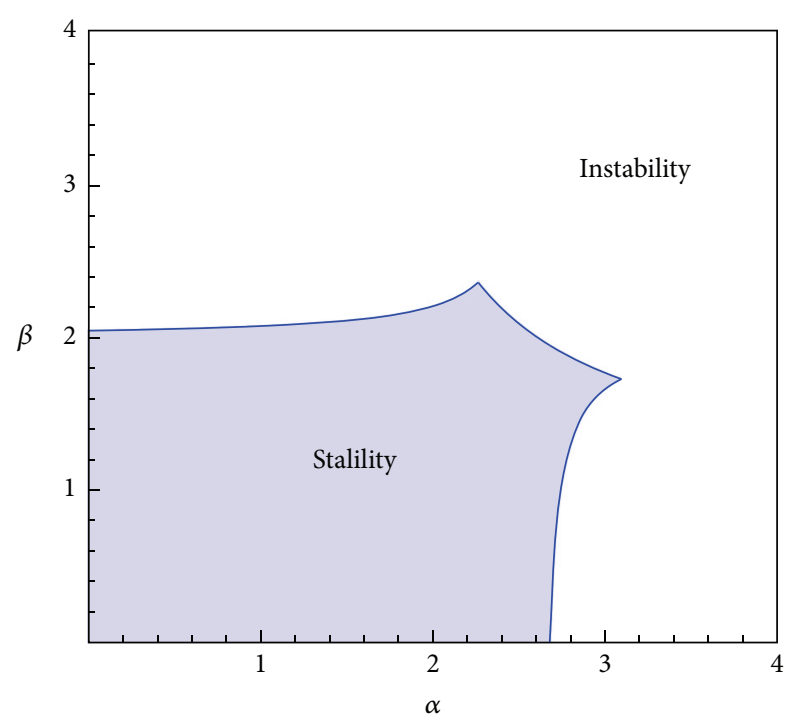

FIGURE 1: The stability and instability region of the Nash equilibrium point $E^{*}$ of system (10).

$$
\begin{aligned}
& \frac{4\left(\alpha(c-1)\left(k^{3}-2 k^{2}-k+2\right)-3 k^{2}+4\right)}{\left(c\left(2 k^{2}-k-2\right)+k^{2}+k-2\right)(\alpha(c-1)(k-2)-4)} \\
& \quad<\beta \\
& \quad<\frac{2 \alpha(c-1)\left(k^{3}-2 k^{2}-k+2\right)}{\left(c\left(2 k^{2}-k-2\right)+k^{2}+k-2\right)(\alpha(c-1)(k-2)-2)} .
\end{aligned}
$$

When $c=0.1, k=0.3$, Figure 1 gives the stability and instability region of the Nash equilibrium point $E^{*}$ in $(\alpha, \beta)$ plane. From the figure, we can conclude that (a) too high speed of adjustment will make the Nash equilibrium point $E^{*}$ lose stability, (b) the stability region is asymmetric, and the adjustment speed of price is more sensitive than the speed of output. When $\alpha>2.65$, the Nash equilibrium point will lose stability, while about $\beta>2.0$, the Nash equilibrium point will do that.

3.2. Bifurcations and Chaotic Behaviors. In this section, we will show the complex behaviors of the system (10), including bifurcation phenomenon and strange attractor, using parameter basin plots (also called 2-D bifurcation diagrams) which is a more powerful tool in the numerical analysis of nonlinear dynamics than the 1-D bifurcation diagrams [25]. Conveniently, we take the parameter values as follows: $c=0.1$ and $k=0.3$. The initial values are chosen as $\left(Q_{1}(0), P_{2}(0)\right)=$ $(0.25,0.20)$. Through (12) in this case, the Nash equilibrium point is $\left(Q_{1}^{*}, P_{2}^{*}\right)=(0.4102,0.4885)$.

Figure 2 presents the parameter basin plots in the $(\alpha, \beta)$ plane with $k=0.3$, in which different colors represent different states. The dark blue indicates stable steady state, light blue for stable cycles of period 2, purple for period 4, green for period 8 , red for cycles of odd period, yellow for chaos, and grey for divergence. 


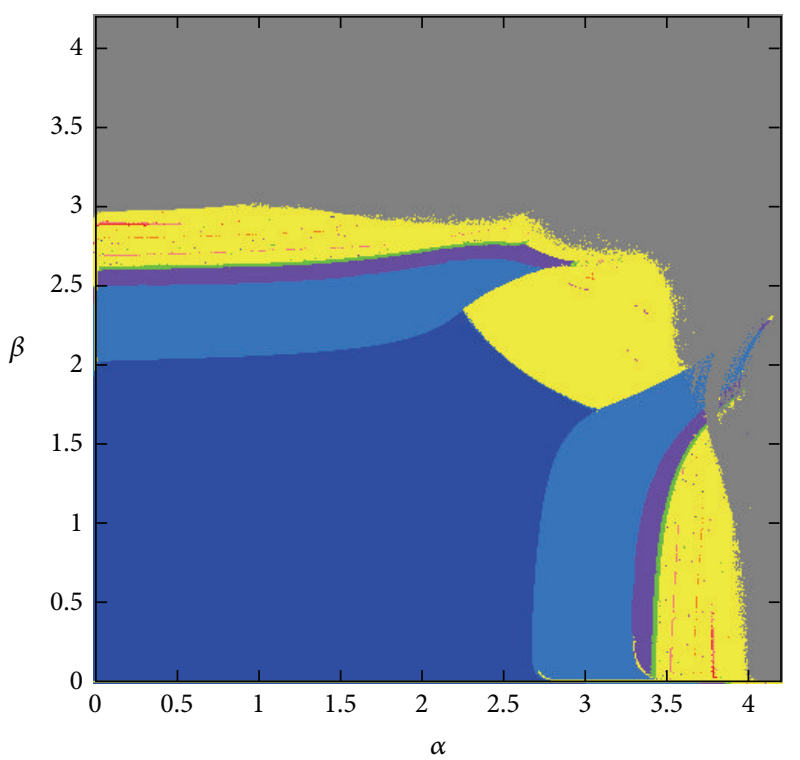

FIgURE 2: The parameter basin plots of system (10) for $k=0.3$.

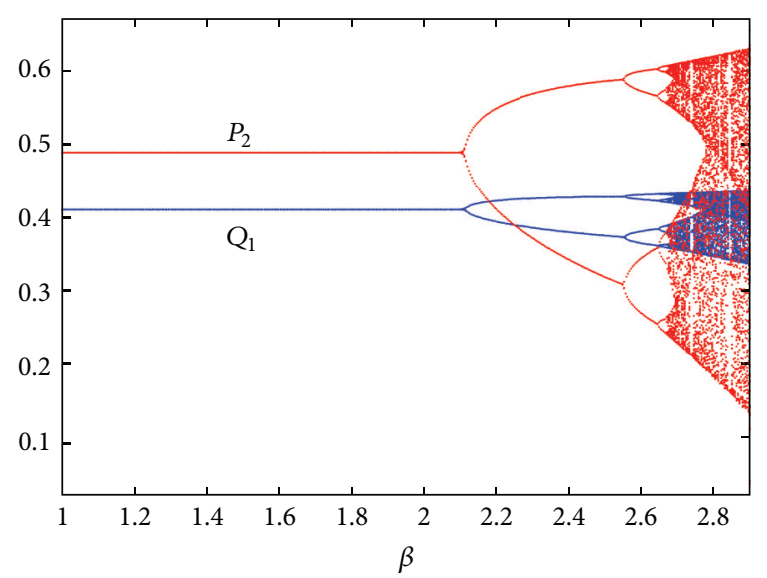

Figure 3: Bifurcation diagrams of system (10) for $\alpha=1.5$ and $\beta$ varying from 1.0 to 2.9 .

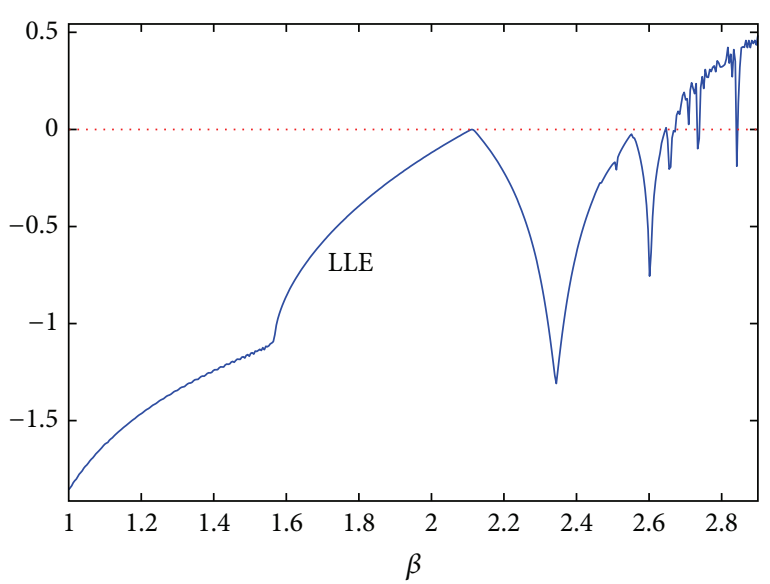

Figure 4: The largest Lyapunov exponent of system (10) for $\alpha=1.5$ and $\beta$ varying from 1.0 to 2.9 .

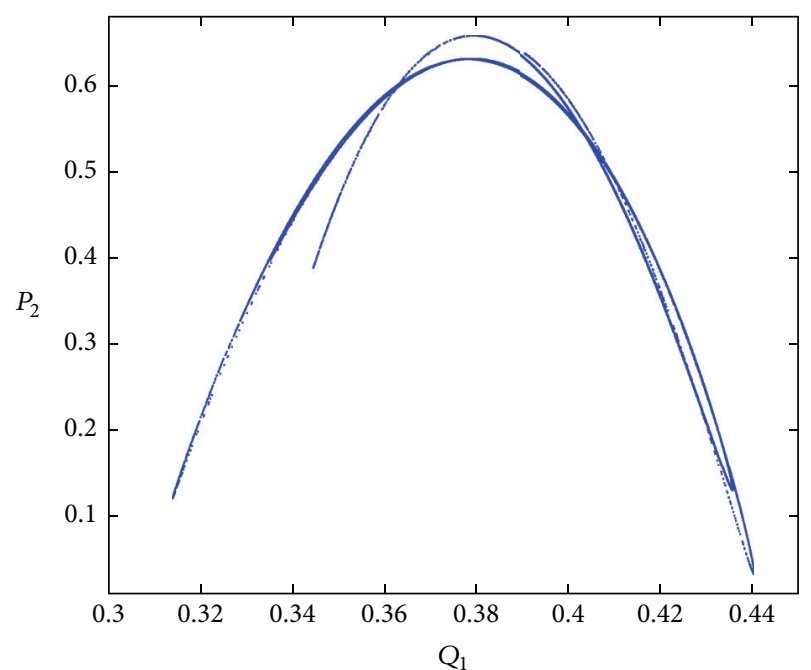

FIGURE 5: The strange attractor of system (10) for $\alpha=1.5$ and $\beta=$ 2.9.

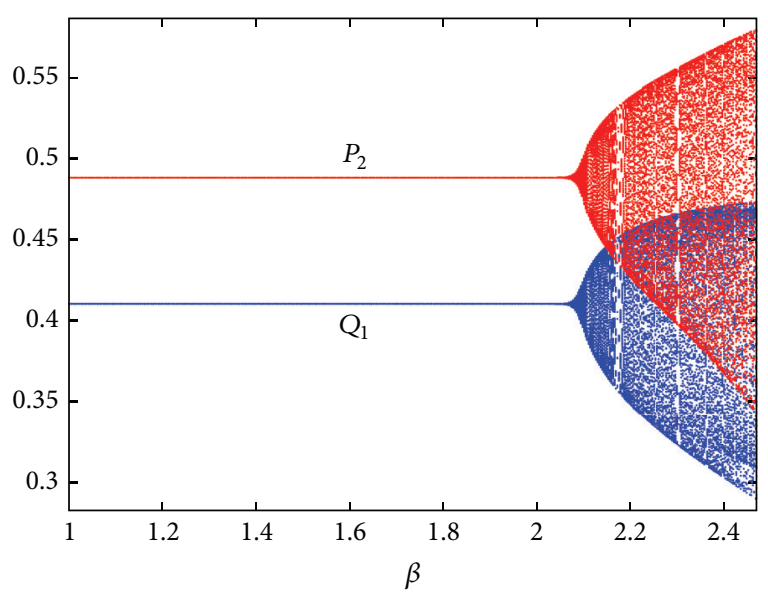

Figure 6: Bifurcation diagrams of system (10) for $\alpha=2.5$ and $\beta$ varying from 1.0 to 2.47 .

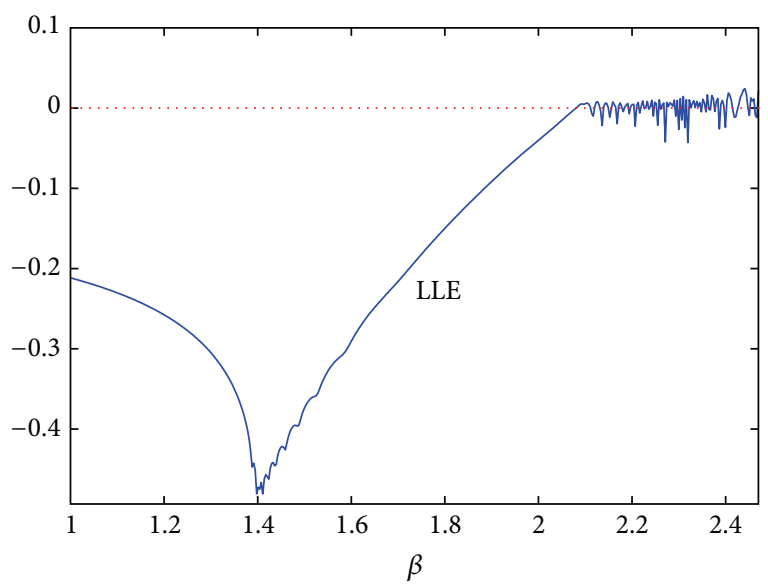

FIGURE 7: The largest Lyapunov exponent of system (10) for $\alpha=2.5$ and $\beta$ varying from 1.0 to 2.47 . 


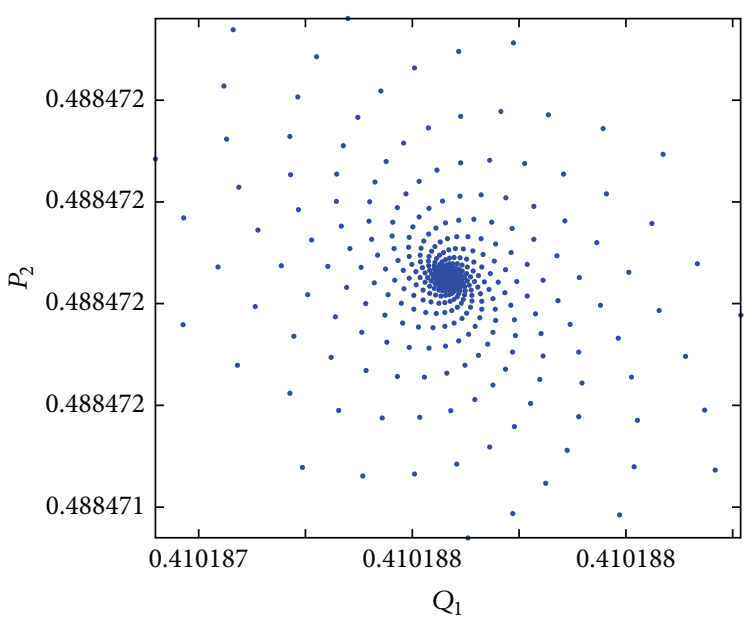

(a) $\beta=2.07$

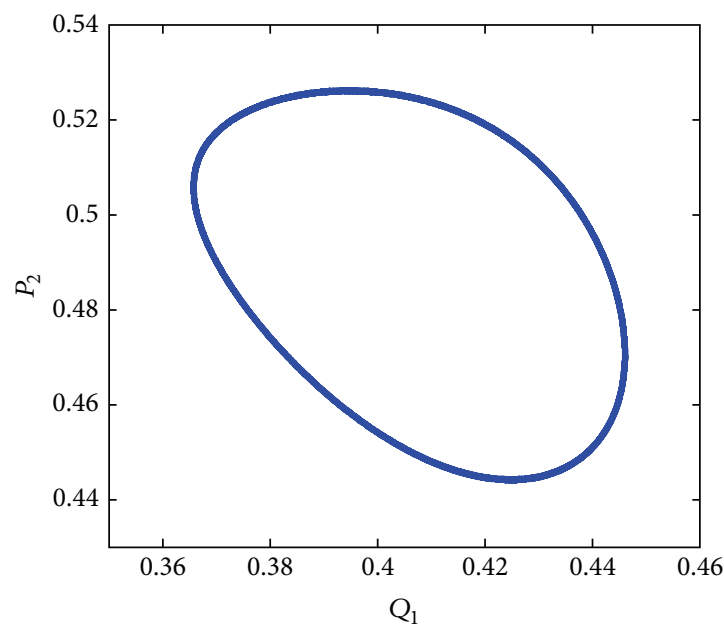

(c) $\beta=2.15$

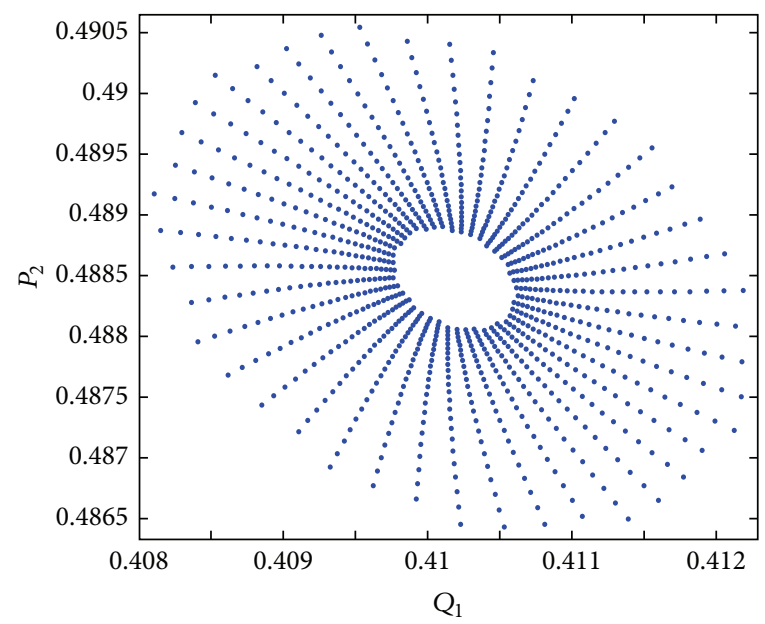

(b) $\beta=2.09$

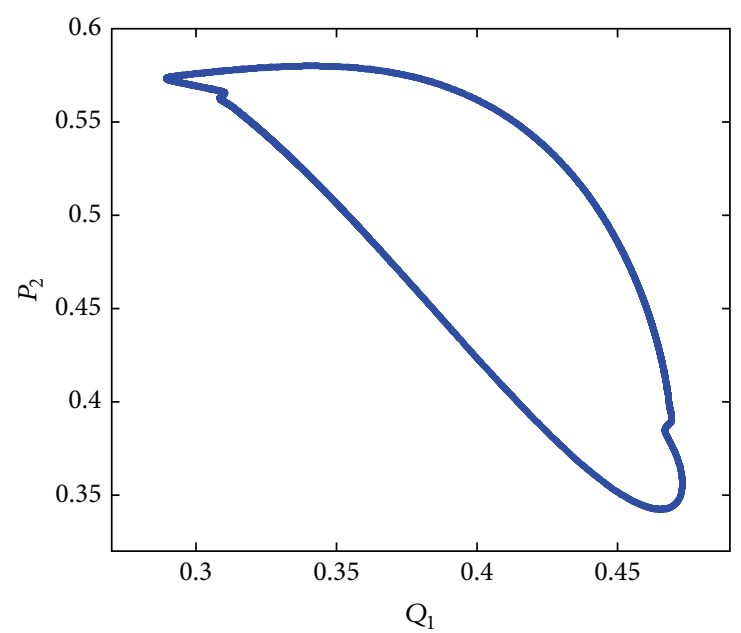

(d) $\beta=2.47$

FIGURE 8: The phase space diagrams of system (10) for $\alpha=2.5$.

We can conclude these results.

(1) When the parameters $(\alpha, \beta)$ from the dark blue area pass through light blue, purple, green, and yellow areas in turn, system (10) enters into chaos through flip bifurcation. Figure 3 shows the bifurcation diagrams of system (10) for $\alpha=1.5$ and $\beta$ varying from 1.0 to 2.9 , and Figure 4 gives the corresponding largest Lyapunov exponent (LLE). When $\alpha=1.5$ and $\beta=$ 2.9 , the system has positive LLE, and then it is in a chaotic state. Figure 5 illustrates the strange attractor of system (10) for $\alpha=1.5$ and $\beta=2.9$.

(2) When $(\alpha, \beta)$ from the dark blue area go directly to the yellow area, system (10) enters into chaos through Neimark-Sacker bifurcation. Figure 6 shows the bifurcation diagrams of system (10) for $\alpha=2.5$ and $\beta$ varying from 1.0 to 2.47, and Figure 7 gives the corresponding LLE. Figure 8 gives the phase space diagrams of system (10) for $\alpha=2.5$, and we can find with the increase of $\beta$, the system generates cycle (as in Figures $8(a)-8(c)$ ), and then the cycle is destroyed, and a strange attractor is developed (as in Figure 8(d)).

(3) When $(\alpha, \beta)$ from the yellow area go directly to the grey area, one of variables of system (10) will overflow, which means that one of the players will be out of the market in economics.

(4) We also note that there are red lines (odd cycles) in the yellow (chaos) region; that is, there are intermittent odd cycles in the chaos. It is well known that a cycle with odd period implies chaotic dynamical behaviors according to the famous "Period 3 implies chaos" result of Li and Yorke, the socalled topological chaos [25].

From the perspective of economics, the players' adjustment speed $\alpha$ and $\beta$ should be in a certain range; otherwise, the system will come forth cycle fluctuations through flip or Neimark-Sacker bifurcations, and then into chaos, which means irregular, unpredictable, sensitive to initial values and 


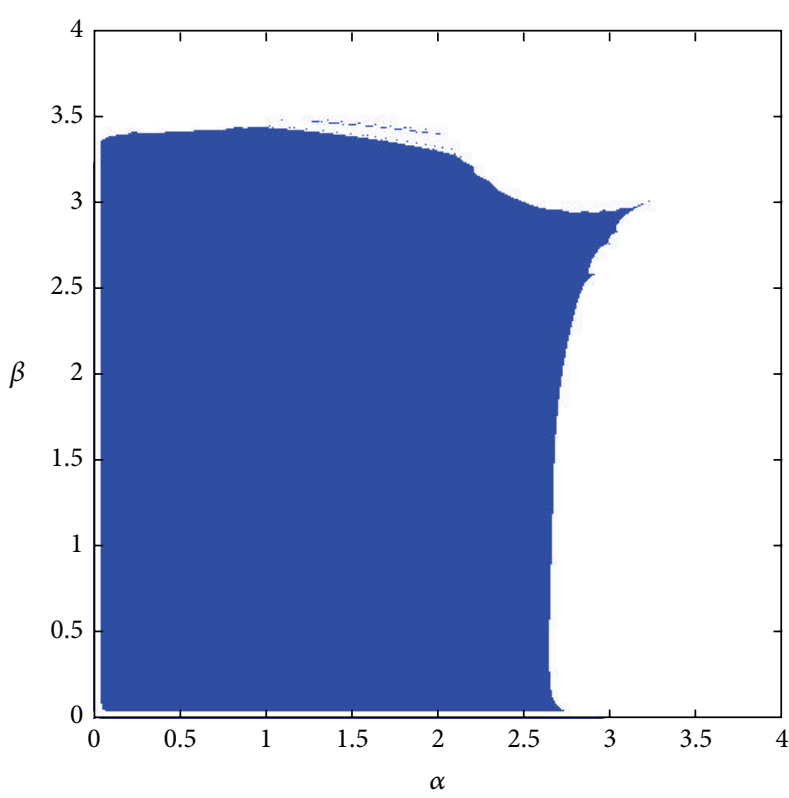

(a) $\omega_{1}=1, \omega_{2}=0.8$

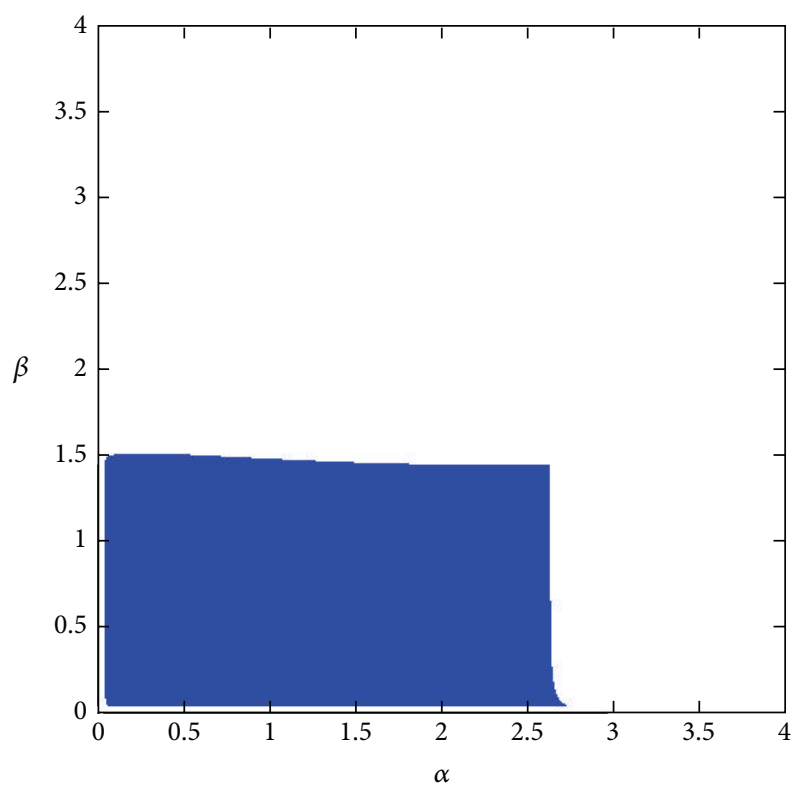

(c) $\omega_{1}=1, \omega_{2}=0.4$

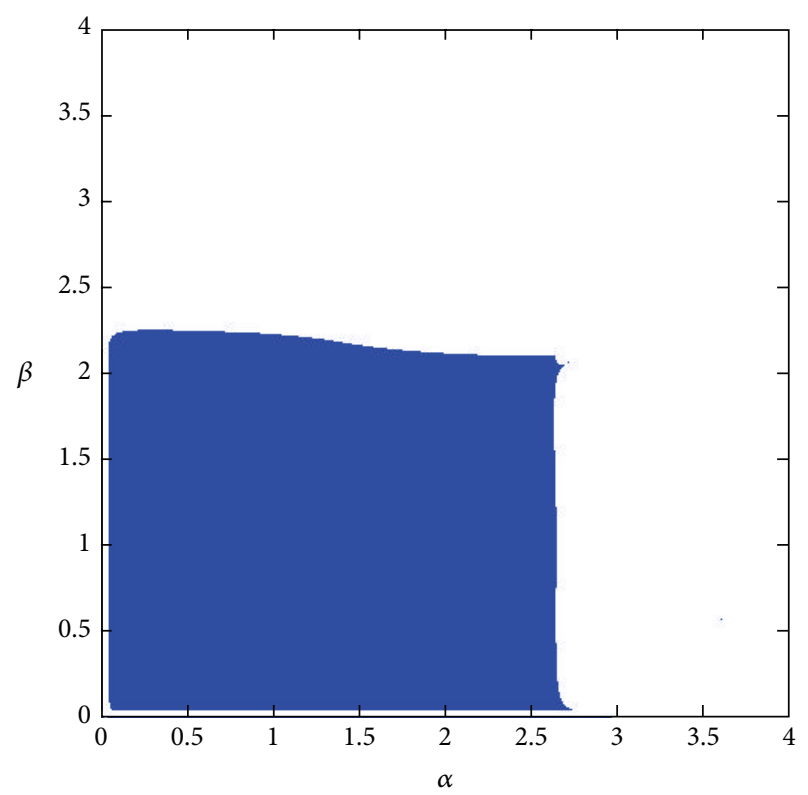

(b) $\omega_{1}=1, \omega_{2}=0.6$

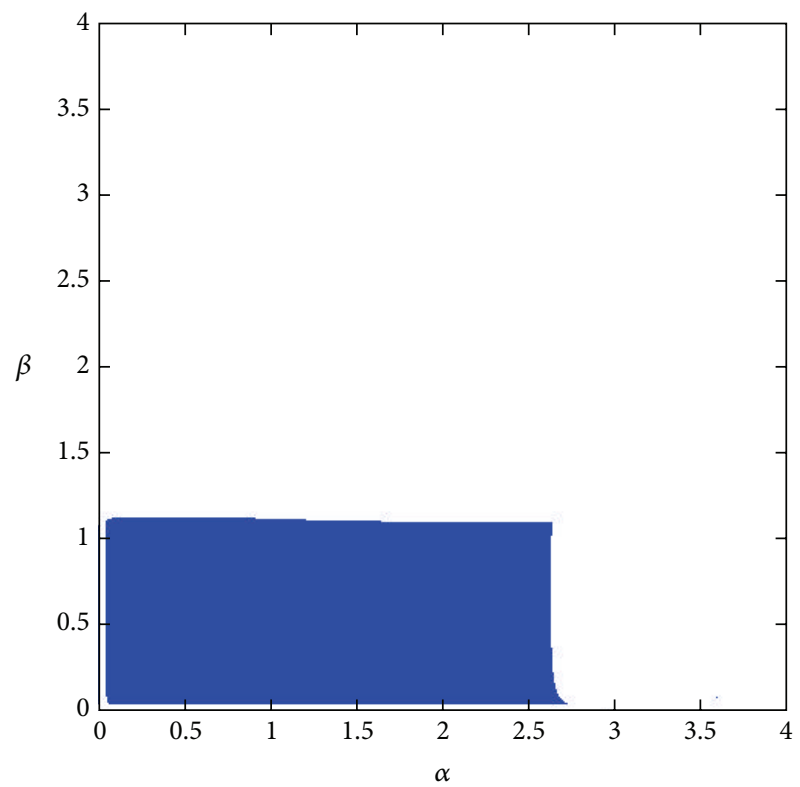

(d) $\omega_{1}=1, \omega_{2}=0.2$

FIgURE 9: The stability region (dark blue) of the Nash equilibrium point $E^{*}$ of system (11) with $\omega_{1}=1$ and $\omega_{2}$ varying.

bad for the economy. We also find that the adjustable range of $\alpha$ is larger than that of $\beta$, which means that the adjustment of price is more sensitive than that of output, and price war will be easier to get market into chaos.

\section{The Dynamics of the Delayed Cournot-Bertrand Mixed System}

4.1. Equilibrium Points and Local Stability. Let $Q_{1}(t+1)=$ $Q_{1}(t)=Q_{1}(t-1), P_{2}(t+1)=P_{2}(t)=P_{2}(t-1)$, and the delayed system (11) has the same equilibrium points as the system (10).
To study the stability of system (11), we can rewrite it as a fourth-dimensional system in the form

$$
\begin{aligned}
& Q_{1}(t+1) \\
& =Q_{1}(t)+\alpha Q_{1}(t) \\
& \times\left(\omega _ { 1 } \left(1-c-k+k P_{2}(t)-2 Q_{1}(t)\right.\right. \\
& \left.\quad+2 k^{2} Q_{1}(t)\right)+\left(1-\omega_{1}\right) \\
& \times\left(1-c-k+k \bar{P}_{2}(t)\right. \\
& \left.\left.-2 \bar{Q}_{1}(t)+2 k^{2} \bar{Q}_{1}(t)\right)\right)
\end{aligned}
$$




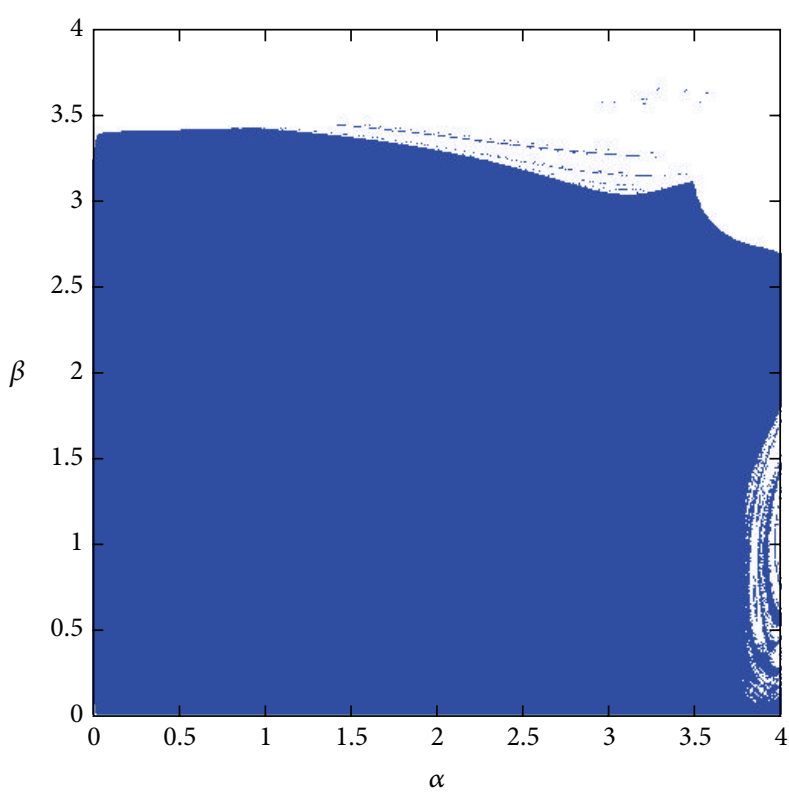

(a) $\omega=0.8$

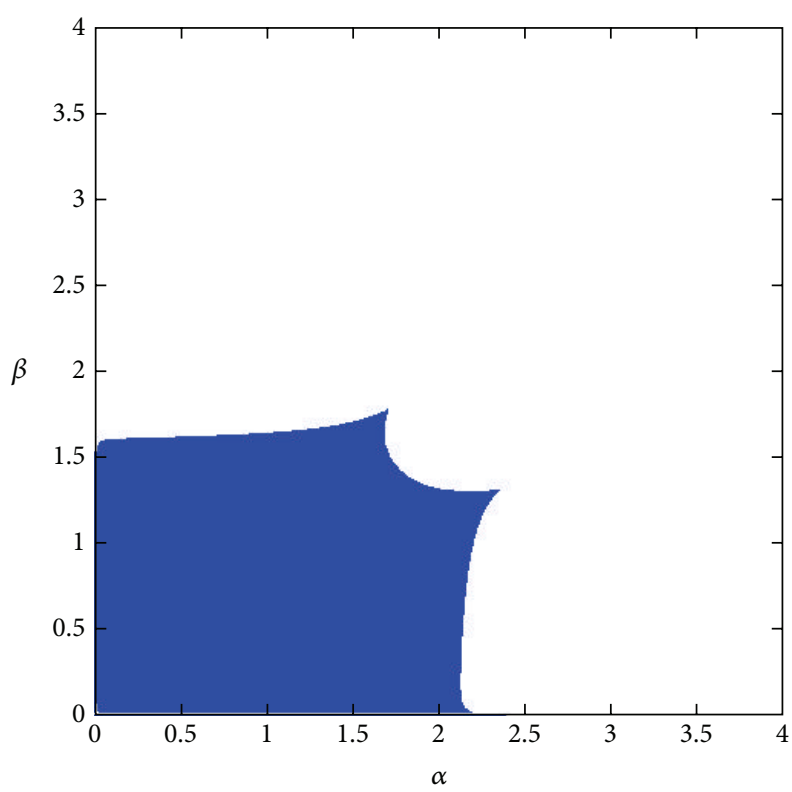

(c) $\omega=0.4$

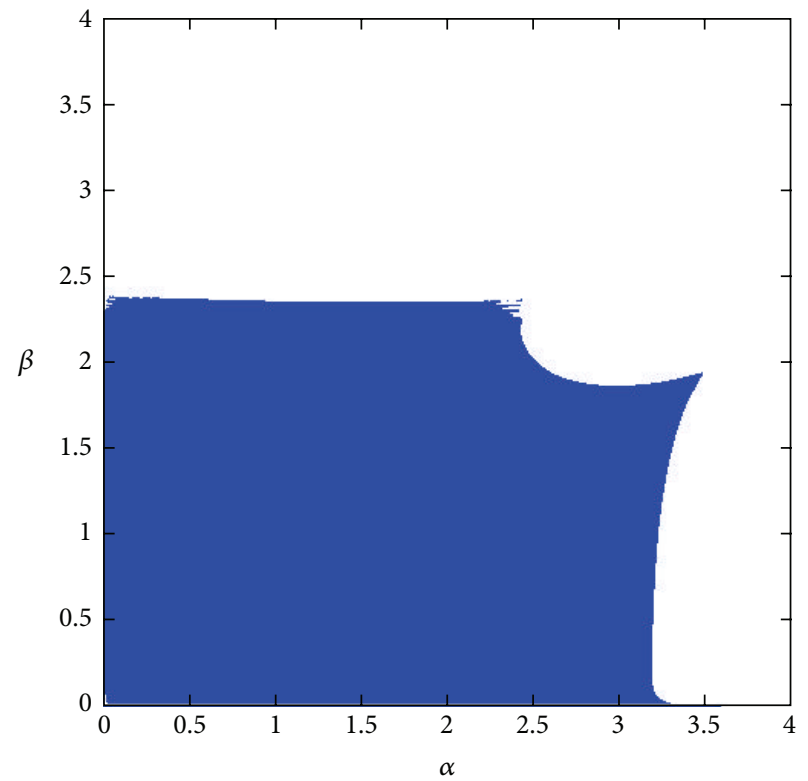

(b) $\omega=0.6$

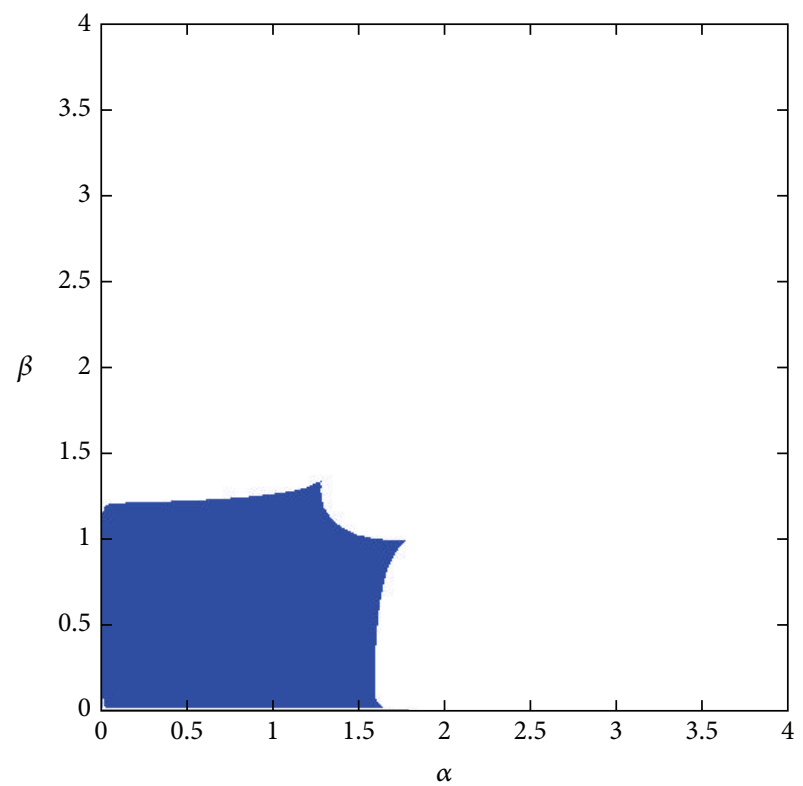

(d) $\omega=0.2$

FIgURE 10: The stability region (dark blue) of the Nash equilibrium point $E^{*}$ of system (11) with $\omega_{1}=\omega_{2}=\omega$ varying.

$$
\begin{aligned}
& \bar{Q}_{1}(t+1)=Q_{1}(t), \\
& P_{2}(t+1) \\
& =P_{2}(t)+\beta P_{2}(t) \\
& \quad \times\left(\omega_{2}\left(1+c-2 P_{2}(t)-k Q_{1}(t)\right)\right.
\end{aligned}
$$

$$
\begin{aligned}
& \left.+\left(1-\omega_{2}\right)\left(1+c-2 \bar{P}_{2}(t)-k \bar{Q}_{1}(t)\right)\right), \\
& \bar{P}_{2}(t+1)=P_{2}(t) .
\end{aligned}
$$

The Jacobian matrix of the system (20) corresponding to the state variables $\left(Q_{1}, \bar{Q}_{1}, P_{2}, \bar{P}_{2}\right)$ is as follows: 


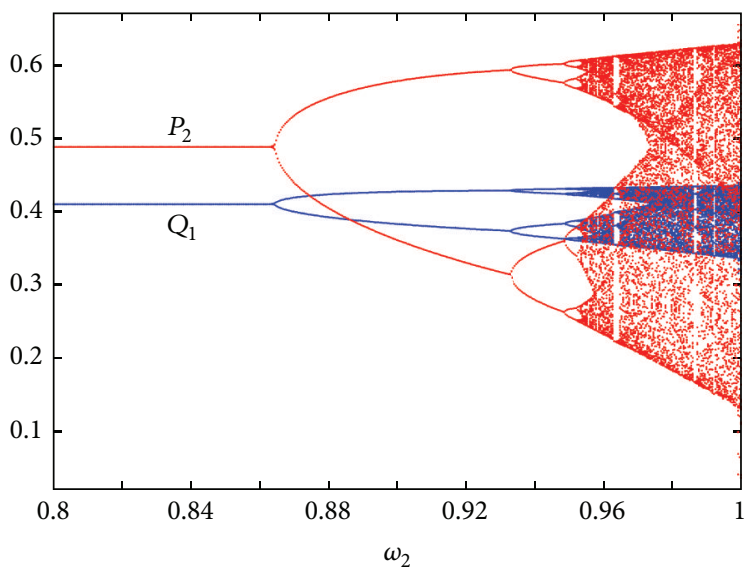

FIGURE 11: Bifurcation diagrams of system (11) for $\alpha=1.5, \beta=2.9$, $\omega_{1}=1$ and $\omega_{2}$ varying from 0.8 to 1 .

$$
\begin{aligned}
& J\left(Q_{1}, \bar{Q}_{1}, P_{2}, \bar{P}_{2}\right) \\
& =\left(\begin{array}{cccc}
J_{11} & -2 \alpha\left(k^{2}-1\right) Q_{1}\left(\omega_{1}-1\right) & \alpha k Q_{1} \omega_{1} & -\alpha k Q_{1}\left(\omega_{1}-1\right) \\
1 & 0 & 0 & 0 \\
-\beta k P_{2} \omega_{2} & \beta k P_{2}\left(\omega_{2}-1\right) & J_{33} & 2 \beta P_{2}\left(\omega_{2}-1\right) \\
0 & 0 & 1 & 0
\end{array}\right),
\end{aligned}
$$

where

$$
\begin{gathered}
J_{11}=1-\alpha\left(2\left(\bar{Q}_{1}\left(\omega_{1}-1\right)-2 Q_{1} \omega_{1}\right) k^{2}\right. \\
+\left(\bar{P}_{2}\left(\omega_{1}-1\right)-P_{2} \omega_{1}+1\right) k \\
\left.+c+2 \bar{Q}_{1}+4 Q_{1} \omega_{1}-2 \bar{Q}_{1} \omega_{1}-1\right), \\
J_{33}=\beta\left(c-k \bar{Q}_{1}+2 \bar{P}_{2}\left(\omega_{2}-1\right)-4 P_{2} \omega_{2}\right. \\
\left.-k Q_{1} \omega_{2}+k \bar{Q}_{1} \omega_{2}+1\right)+1 .
\end{gathered}
$$

Similarly, the local stability of equilibrium points can be determined by the nature of the eigenvalues of the Jacobian matrix evaluated at the corresponding equilibrium points. As in the system (10), we can easily conclude that the boundary equilibrium points $E_{0}, E_{1}$, and $E_{2}$ are not stable.

In this case, because of the computational complexity, it is hard to give the analytical expression of local stable regions of the only Nash equilibrium points $E^{*}$ by Jury conditions as in system (10). In order to find the influences of delay on the stability of $E^{*}$, using numerical method as in [25], Figure 9 separately gives the stability region (dark blue) of the Nash equilibrium point $E^{*}$ of system (11) for $\omega_{1}=1, \omega_{2}=0.8$, $0.6,0.4$ and 0.2 , and Figure 10 gives the stability region of the Nash equilibrium point $E^{*}$ of system (11) for $\omega_{1}=\omega_{2}=\omega=$ $0.8,0.6,0.4$ and 0.2 , respectively. From the comparison with Figure $1\left(\omega_{1}=\omega_{2}=1\right)$, we can see with the decreasing of the delay weights that the dark blue area first becomes bigger and then smaller; that is, the stability of Nash equilibrium is increased if less weights are put on the more recent price or quantity and price simultaneously; otherwise, the region of stability becomes smaller.

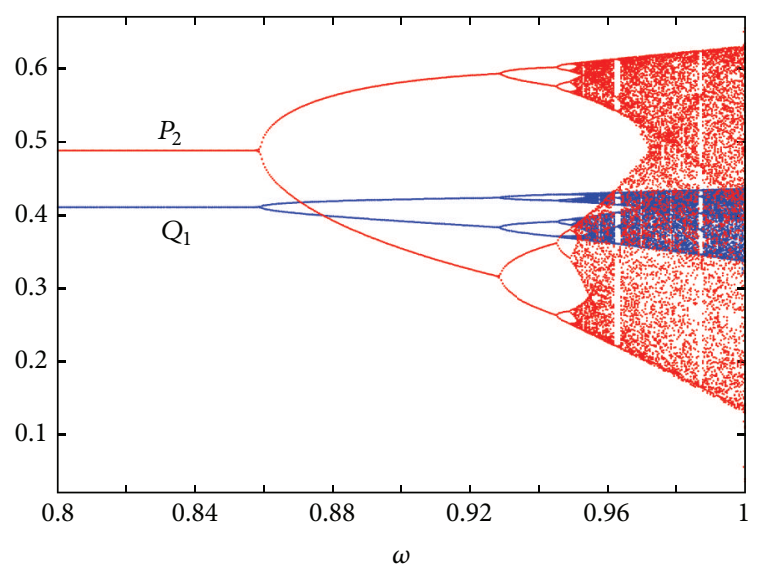

FIGURE 12: Bifurcation diagrams of system (11) for $\alpha=1.5, \beta=2.9$ and $\omega_{1}=\omega_{2}=\omega$ varying from 0.8 to 1 .

4.2. The Effects of Delay on System Stability. Numerical simulations are carried to show the influences of the delay weights on system (11). When $\alpha=1.5$ and $\beta=2.9$, according to Figure 3, the nondelayed system is in chaos through flip bifurcation. Figure 11 shows bifurcation diagrams of system (11) for $\alpha=1.5, \beta=2.9, \omega_{1}=1$ and $\omega_{2}$ varying from 0.8 to 1 . Figure 12 shows bifurcation diagrams of system (11) for $\alpha=1.5, \beta=2.9$ and $\omega_{1}=\omega_{2}=\omega$ varying from 0.8 to 1 . It can be seen that the chaotic system can be controlled to stable states or cycles by selecting suitable delay weight values; that is, the introduction of the lagged structure can make the system have a higher chance of reaching steady states.

When $\alpha=2.5$ and $\beta=2.3$, according to Figure 6, the nondelayed system is in chaos through Neimark-Sacker bifurcation. Figure 13 shows bifurcation diagrams of system (11) for $\alpha=2.5, \beta=2.3, \omega_{1}=1$ and $\omega_{2}$ varying from 0.8 to 1 . Figure 14 shows bifurcation diagrams of system (11) for $\alpha=2.5, \beta=2.3$ and $\omega_{1}=\omega_{2}=\omega$ varying from 0.8 to 1 . It can be seen that the chaotic system can also be controlled to stable states by selecting suitable delay weight values.

Above all, if the system is in chaos, either through flip or Neimark-Sacker bifurcation, reasonably selecting delay weights can help control chaos to cycles or stable states. So making full use of the historical data can improve the system's stability.

\section{Conclusions}

In this paper, we propose a delayed Cournot-Bertrand mixed game model, assuming that the demand and cost function is linear, and the firms make their decisions according to their own marginal profit. Through comparison with the nondelayed model, we find that they have the same equilibrium points, the boundary equilibrium points are always unstable, and the local stability of the Nash equilibrium is affected by the weights of delay. If less weights are put on the more recent quantity and price, the stability region of Nash equilibrium will become bigger, otherwise it will become smaller. Moreover, we analyze the effects of the delay on the 


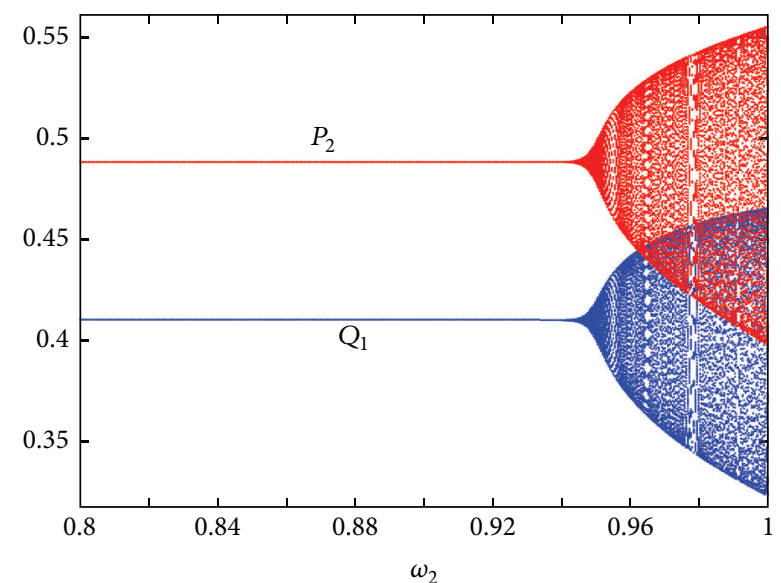

FIGURE 13: Bifurcation diagrams of system (11) for $\alpha=2.5, \beta=2.3$, $\omega_{1}=1$ and $\omega_{2}$ varying from 0.8 to 1 .

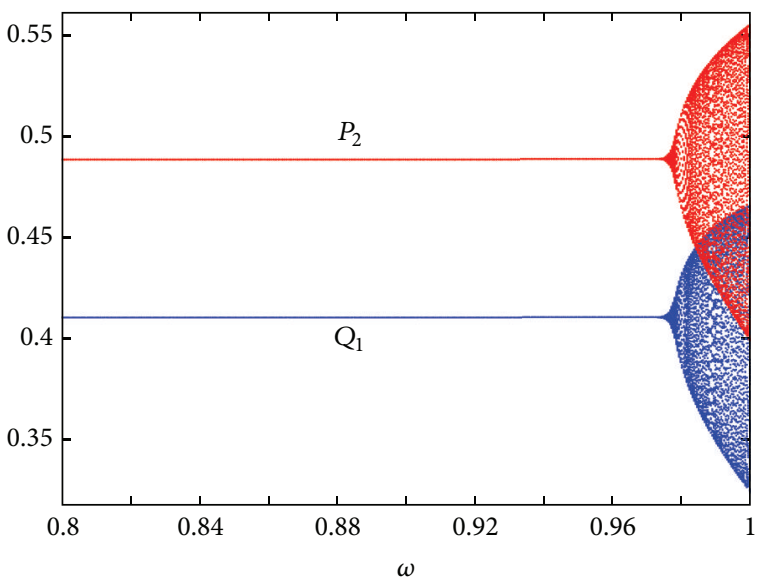

Figure 14: Bifurcation diagrams of system (11) for $\alpha=2.5, \beta=2.3$ and $\omega_{1}=\omega_{2}=\omega$ varying from 0.8 to 1 .

system stability and find that making full use of the memory can help control chaos to cycles or stable states.

\section{Acknowledgments}

The authors thank the reviewers for their careful reading and providing some pertinent suggestions. The research was supported by the National Natural Science Foundation of China (no. 61273231).

\section{References}

[1] J. Friedman, Oligopoly Theory, Cambridge University Press, Cambridge, UK, 1983.

[2] T. Puu and I. Sushko, Oligopoly Dynamics: Models and Tools, Springer, New York, NY, USA, 2002.

[3] G. I. Bischi, C. Chiarella, M. Kopel, and F. Szidarovszky, Nonlinear Oligopolies: Stability and Bifurcations, Springer, New York, NY, USA, 2010.
[4] T. Puu, Oligopoly: Old Ends-New Means, Springer, New York, NY, USA, 2010.

[5] H. Wang and J. Ma, "Complexity analysis of a CournotBertrand duopoly game model with limited information," Discrete Dynamics in Nature and Society, vol. 2013, Article ID 287371, 6 pages, 2013.

[6] C. H. Tremblay and V. J. Tremblay, "The Cournot-Bertrand model and the degree of product differentiation," Economics Letters, vol. 111, no. 3, pp. 233-235, 2011.

[7] A. K. Naimzada and F. Tramontana, "Dynamic properties of a Cournot-Bertrand duopoly game with differentiated products," Economic Modelling, vol. 29, no. 4, pp. 1436-1439, 2012.

[8] J. Ma and X. Pu, “The research on cournotcbertrand duopoly model with heterogeneous goods and its complex characteristics," Nonlinear Dynamics, vol. 72, no. 4, pp. 895-903, 2013.

[9] S. Bylka and J. Komar, "Cournot-bertrand mixed oligopolies," in Warsaw Fall SemInars in Mathematical Economics, pp. 22-33, Springer, New York, NY, USA.

[10] X. Vives, "On the efficiency of Bertrand and Cournot equilibria with product differentiation," Journal of Economic Theory, vol. 36, no. 1, pp. 166-175, 1985.

[11] S. D. Sklivas, "The strategic choice of managerial incentives," Rand Journal of Economics, vol. 18, no. 3, pp. 452-458, 1987.

[12] J. Häckner, "A note on price and quantity competition in differentiated oligopolies," Journal of Economic Theory, vol. 93, no. 2, pp. 233-239, 2000.

[13] P. Zanchettin, "Differentiated duopoly with asymmetric costs," Journal of Economics and Management Strategy, vol. 15, no. 4, pp. 999-1015, 2006.

[14] A. Arya, B. Mittendorf, and D. E. M. Sappington, "Outsourcing, vertical integration, and price versus quantity competition," International Journal of Industrial Organization, vol. 26, no. 1, pp. 1-16, 2008.

[15] T. Sato, "On Cournot-Bertrand mixed duopolies," Japanese Economic Review, vol. 47, no. 4, pp. 412-420, 1996.

[16] E. Ahmed, H. N. Agiza, and S. Z. Hassan, "On modifications of Puu's dynamical duopoly," Chaos, Solitons and Fractals, vol. 11, no. 7, pp. 1025-1028, 2000.

[17] H. N. Agiza, A. S. Hegazi, and A. A. Elsadany, "The dynamics of Bowley's model with bounded rationality," Chaos, Solitons and Fractals, vol. 12, no. 9, pp. 1705-1717, 2001.

[18] M. T. Yassen and H. N. Agiza, "Analysis of a duopoly game with delayed bounded rationality," Applied Mathematics and Computation, vol. 138, no. 2, pp. 387-402, 2003.

[19] S. Z. Hassan, "On delayed dynamical duopoly," Applied Mathematics and Computation, vol. 151, no. 1, pp. 275-286, 2004.

[20] A. A. Elsadany, "Dynamics of a delayed duopoly game with bounded rationality", Mathematical and Computer Modelling, vol. 52, no. 9-10, pp. 1479-1489, 2010.

[21] A. Matsumoto and F. Szidarovszky, "Delayed dynamics in heterogeneous competition with product differentiation," Nonlinear Analysis: Real World Applications, vol. 11, no. 2, pp. 601611, 2010

[22] J. Peng, Z. Miao, and F. Peng, "Study on a 3-dimensional game model with delayed bounded rationality," Applied Mathematics and Computation, vol. 218, no. 5, pp. 1568-1576, 2011.

[23] J. Ma and J. Zhang, "Research on the price game and the application of delayed decision in oligopoly insurance market," Nonlinear Dynamics, vol. 70, no. 4, pp. 2327-2341, 2012. 
[24] S. Elaydi, An Introduction to Difference Equations, Springer, New York, NY, USA, 2005.

[25] C. Diks, C. Hommes, V. Panchenko, and R. van der Weide, "E\&F chaos: a user friendly software package for nonlinear economic dynamics," Computational Economics, vol. 32, no. 1-2, pp. 221244, 2008. 


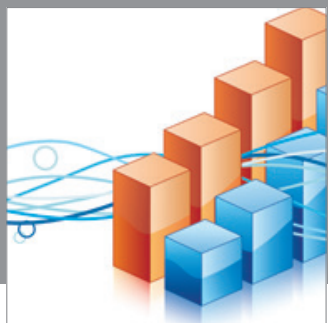

Advances in

Operations Research

mansans

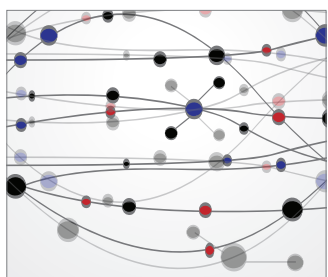

The Scientific World Journal
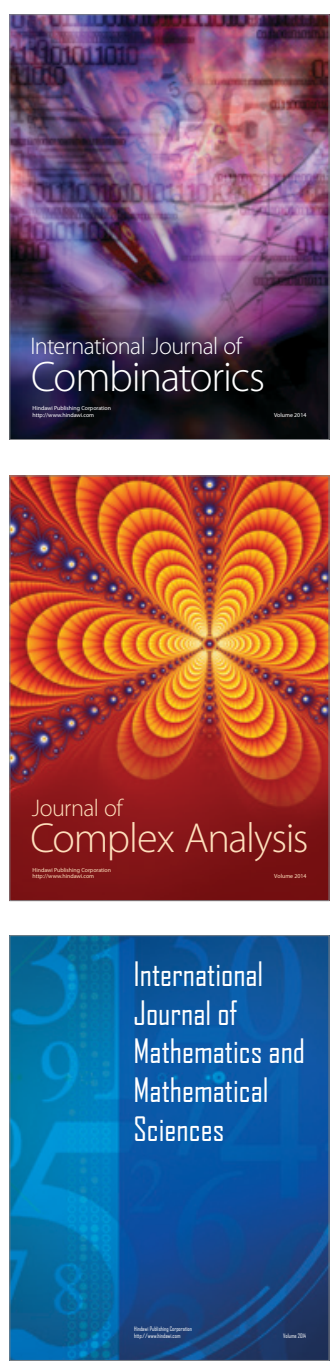
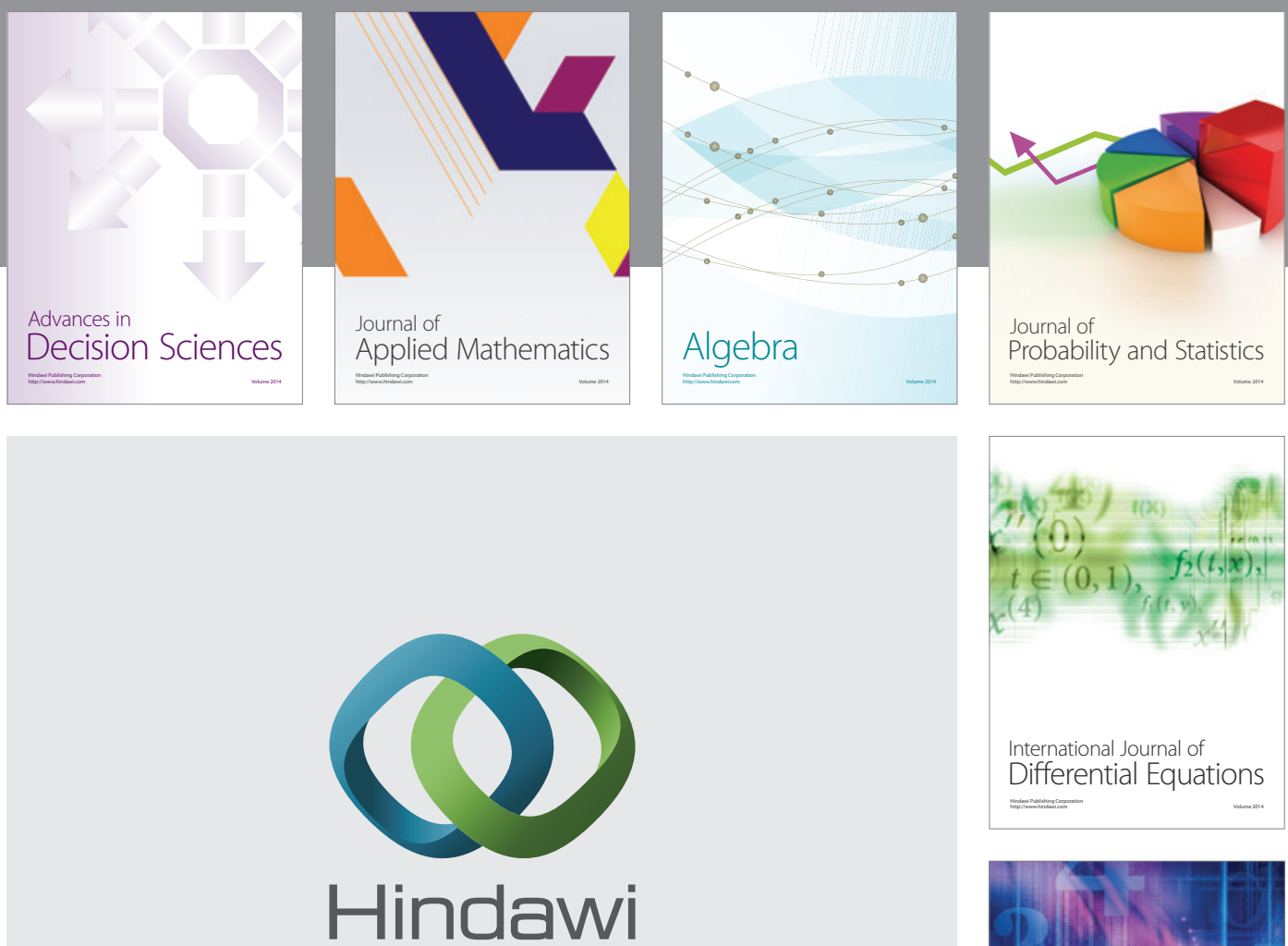

Submit your manuscripts at http://www.hindawi.com
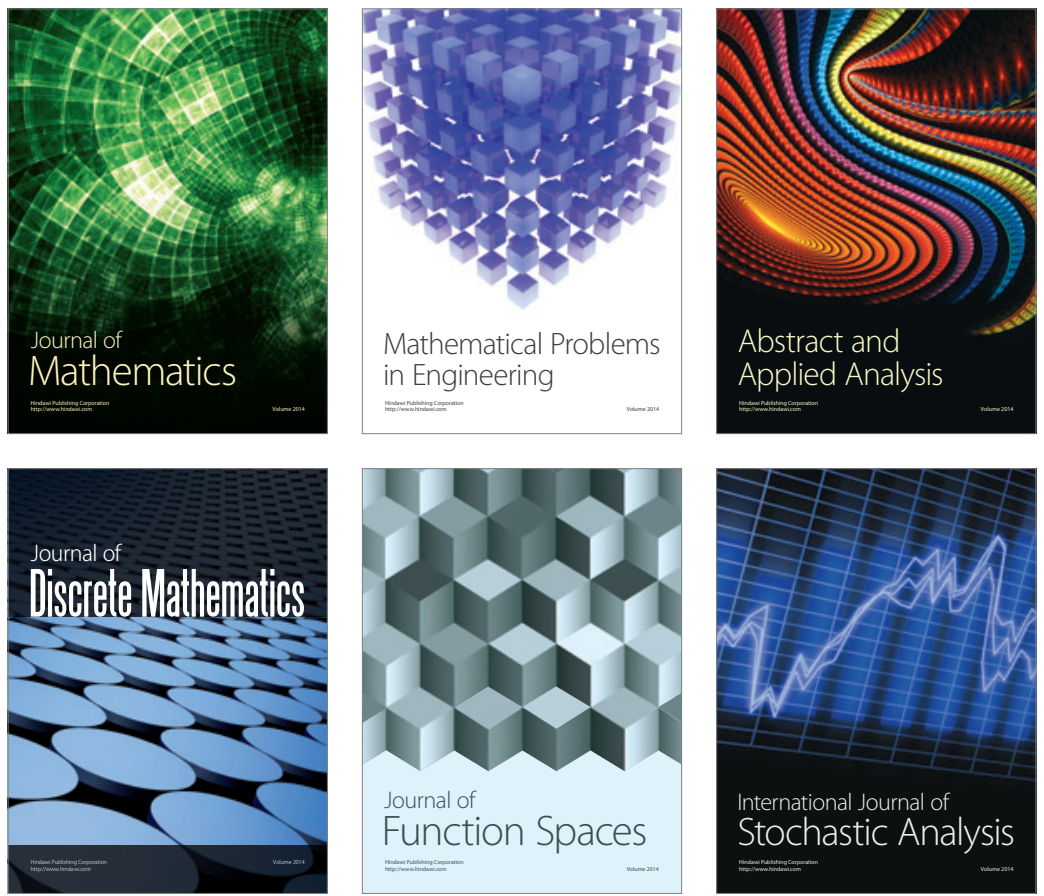

Journal of

Function Spaces

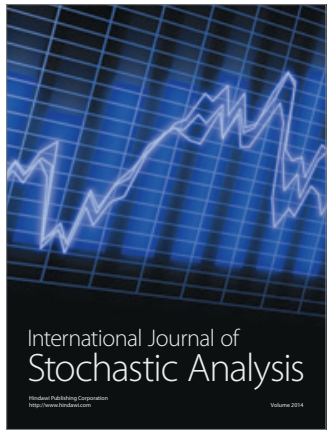

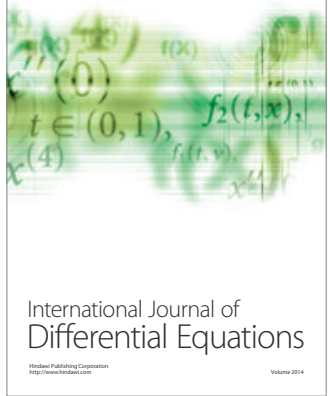
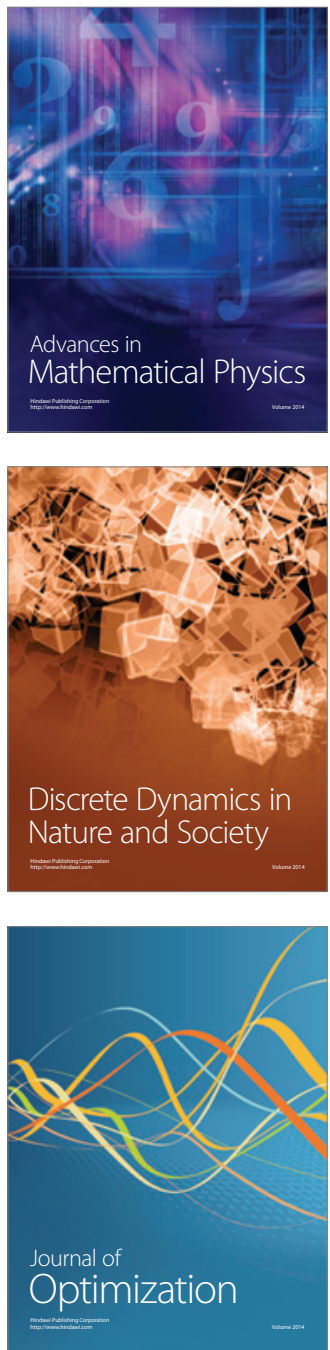